\title{
The Application of Policy Leverage in Promoting the Sustainable Development of Intermodal Freight Transport
}

\author{
Yu Yuan \\ China Academy of Transportation Sciences, Research Centre of Comprehensive transportation, 100029 Beijing, China
}

\begin{abstract}
With the rapid growth of transportation, environmental issues emerges. In order to achieve the society healthy development objective, transportation needs to develop sustainably. This paper proposes that intermodalism is crucial and efficient to transportation sustainability. The traditional intermodal transportation only considers about cost, time and reliability in choosing transportation mode and routes. First, this paper proposes the methodology of sustainable intermodal freight transport, which consider not only temporal and distance attributes, but also cost, energy, and emissions attributes, including emissions of carbon dioxide $\left(\mathrm{CO}_{2}\right)$, particulate matter(PM10), sulfur oxides $\left(\mathrm{SO}_{\mathrm{x}}\right)$, volatile organic compounds $\left(\mathrm{VOC}_{\mathrm{s}}\right)$, and oxides of nitrogen $\left(\mathrm{NO}_{\mathrm{x}}\right)$. Then, this paper indicates that public policies is very important for sustainable transportation, because of the market failure in some cases. At last, the paper propose some policies that will help us a lot to achieve sustainable freight transport. The main policies include mode subsidies, infrastructure investment, economic incentives and technology improvement.
\end{abstract}

\section{Introduction}

In recent years, pollution and environmental issues become the crucial factors when people make decisions. Now they play the paramount important role. This phenomenon appeared in all ranges of our daily life, as well as in all the industries in the world, including the freight transport industry.

Truck and air sectors are traditionally the most energy-intensive and carbon-intensive modes of freight transport. Because truck transport has a higher energyand carbon-intensity compared to rail or ship, these trends do not bode well for developing sustainable freight transportation. One method of reducing the energy use and emissions from freight transportation is intermodalism and mode-shifting.

Previously, when people choose transportation modes or routes, they always consider three factors, which are total travel time, travelling cost as well as reliability. Truck used to be the most popular transport mode in the world. Based on the existing shortest path algorithm, the route with lowest total travel cost will be chosen, if people consider the cost element as the most important. We can also translate total travel time and reliability factors into travel cost, in order to implement the three factors together to help us make decision.

Now, people also began to care the environmental impact of emissions by freight transport. People want to find a method that can be used on freight transport in order to make improvements on the impact on environment. In other words, people are working hard to change the existing freight transport into sustainable freight transport. This shows our responsibility to protect the environment.

We are going to find a way to choose the optimal route based on variety of factors. The method should not only consider traditional factors such as total cost, delivery of time and reliability, but also take energy and environmental factors into consideration.

\section{Methodology}

First, we should construct a hub-and-spoke system to present our real world transport network (Seen as in Fig. 1) $[1]$.

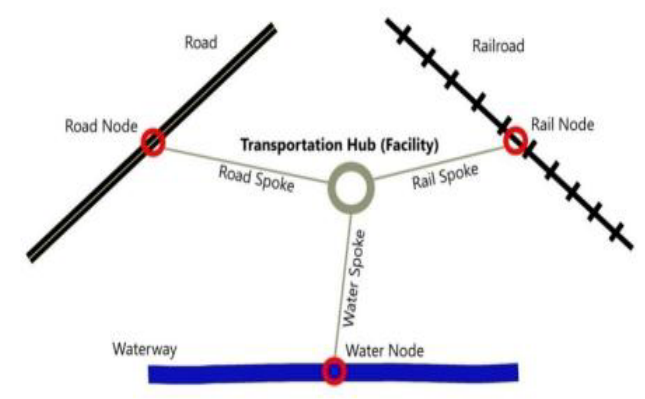

Figure 1. Construction of "hub-and-spoke" network.

Second, we should define our multiple objectives of the freight transport.

Third, translate those non-monetary objectives into monetary objective like the total cost of the route. In this step, we should find and define some criteria to translate them. 
For transport time and transfer time, we can use "value of time" (VOT) to translate them into cost. Specifically, we can adopt Delphi method to determine VOT.

For reliability, we can use a rate to represent the goods' relative importance. The higher value the goods has, the higher rate we'll assign to it. In general, we assign lower cost to the goods that have the higher rates. In this case, there is more to high value than the merely high monetary value of the goods, but also include the need for JIT delivery.

To represent the energy use and emission of a mode, we use an emissions calculator (Seen as in Fig. 2). The inputs of the emission calculator are some general information of the mode we are researching, such as horsepower, fuel economy, and cargo capacity. Then, it can output the cost-factor. An example of cost-factor is the amount of $\mathrm{CO}_{2}$ emitted by a truck carrying a twentyfoot equivalent unit (TEU) container of freight for one mile (grams of $\mathrm{CO}_{2}$ per TEU-mile). In addition, the result of the cost-factors can be modified by general information of specific mode, such as the travel speed, horsepower, fuel types and so on. Having obtain the costfactors, we can use the "price for carbon" to implement the $\mathrm{CO}_{2}$ emissions results into the total cost of the transport route [2].

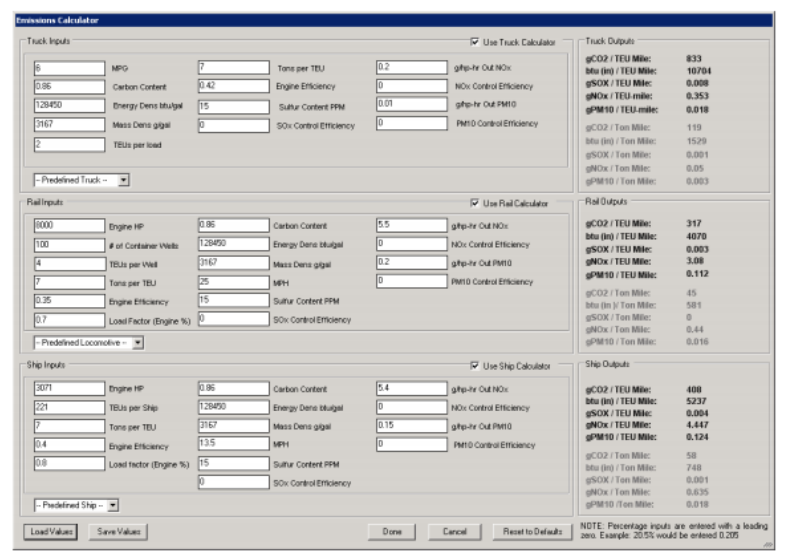

Figure 2. The GIFT Emissions calculator.

At last, the multi-objective problem has been translated into single-objective problem, so we adopt the shortest path algorithm to determine the optimal route we'll choose.

\section{The importance of policies in reducing energy use and emissions in fright transport}

The policies have the power to adjust and control the freight transport industry in a macro scope. It can make up the limitations of market economics, and can powerfully change something in the freight transport industry that the industry can't change to the extent by itself. The policies just give a push to the freight transport industry to reform.

Public policies are necessary to reduce freight transport energy use and emissions in order to: (1) address a market failure; (2) provide economic security.

\subsection{Construct a framework of the policy levers to decrease the energy use and $\mathrm{CO}_{2}$ emissions by freight transport}

First, we construct a framework of policy levers. It includes 6 policy levers that can affect the energy use and emissions of $\mathrm{CO}_{2}$ [3]. They are:

- Mode-shift: use efficient modes

- Fuel: use low-carbon fuel

- Technology: use advanced technology during

- Intermodal freight transport

- Operations: do the best and efficient operations.

- Logistics: improve supply-chain management in

- Order to enhance efficiency

\subsection{Infrastructure investment.}

Infrastructure investment includes 2 kinds of cases. The first case is that we need to build new transfer infrastructure along the routes. Another case is that we need to make extensions on the existing transfer infrastructure, in order to make it become more efficient.

In order to evaluate our infrastructure investment, we need to go through the following 4 steps:

First, we need to know the freight volumes along specific corridors;

Second, we need to measure the costs and benefits of investment;

Third, we need to consider this infrastructure investment from stakeholder's views;

Fourth, we need to know and determine where funding would come from.

A thorough cost-benefit analysis is very important; it helps portray the tradeoffs associated with a proposed public policy.

Stakeholders would include policymakers; the public; freight transport businesses and organizations; and other special interest groups (perhaps environmental groups). If the policy can be shown to result in greater benefits than costs, it is more likely that stakeholders will support the proposal.

Stakeholders will be most interested in where funding would come from. Would the government encourage this investment and provide subsidies or grants for construction? If so, what agencies would disburse these funds and administer such a program? The answers to these questions will help determine the economic and political feasibility of the policy.

Firstly, we should know where major freight flows using containerization exist. This will create an origin and destination pair for the route. Then we may have an idea of potential sites for new intermodal transfer facilities or locations of existing facilities that could be upgraded along those freight corridors.

We use the hub-and-spoke approach. In the network, the transfer facility is the "hub" and the "spokes" are created by a connecting the facility to available road, rail, and water networks.

At last, we can solve an objective function (least-time, least-cost, least- $\mathrm{CO}_{2}$, etc.) from origin and destination before and after adding the new facility and determine if the addition affects the results. 
But for the upgrade of the existing transfer infrastructure, we need to measure how much transfer time can decrease after upgrading the existing transfer infrastructure. So we need to get and know the data of current container handling capacity and container volume through the facility. In this way, we can get the transfer time of the current system. Second, we need to get the data of container handling capacity after upgrading and container volume through the facility now. So we have got the original transfer time and the transfer time after improving the facility. At last, we can get total time reduction achieved by improving the container handling infrastructure at the facility.

Therefore, to reduce the intermodal transfer time for a container, infrastructure investments should affect the rate of incoming container offloading, the on-site capacity for container storage, or the rate of outgoing container loading (or a combination of these variables). (Seen as in Fig. 3)

However, we can't increase just one among the three factors. It's not meaningful to just increase the rate of incoming container offloading if they do not have the ability to store those containers. Also, if the rate of incoming container offloading is greater than the rate of outgoing container loading, there will not be a transfer time reduction.

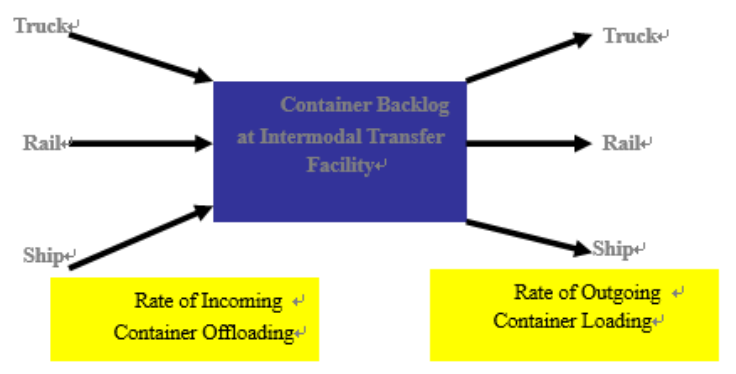

Figure 3. Variables that affect the intermodal transfer time.

\subsubsection{Cost-benefit analysis of infrastructure investment}

The costs of implementing such a policy might include the cost of new container handling equipment, fuel costs for new equipment, construction materials, and labor. In addition, economic loss due to closure or limited use of the facility during the upgrade should be considered.

The benefits of implementing such a policy can be the increased profit because of larger capacity of the new facility; reduced emissions due to more efficient equipment; and the decreasing of transfer times.

\subsubsection{Stakeholders related to this policy}

The stakeholders of facility investment include government (policy makers), public, freight transport companies, and environmental protectors and so on. If it seems to the stakeholders that the benefit of it exceeds the cost, stakeholders will support this proposed policy.
This policy may result in reduction of transfer time. As the transfer time reduced, the total time of intermodal transport will decrease. Intermodal transport offers an important opportunity to lower shipping costs in mediumto long-distance transportation [4]. So many people will turn to use intermodal transport to replace the single truck mode. However, we need to define how many percent of single truck transport will change into intermodal transport.

\subsection{Economic incentives and penalties.}

\subsubsection{Modal subsidies}

1) Definition

Knowing which modes would be subsidized is very important. Truck is the most carbon-intensive and fuel consumption mode. Air transport is also relatively carbon-intensive. Compared with truck and air transport, rail and ship transport are low-carbon transport modes. So government encourages people to use low-carbon transport modes through giving economic incentives to people to make them shift transport modes from truck to rail or ship transport. This means that if you use the government encouraged transportation modes, you will get subsidies, convenience and better service from it. For example, Government may reduce the per container-mile cost for the rail and ship segments of the network.

We need to find appropriate subsidy level. Freight modes like rail and ship are already less expensive than truck, so the point of the subsidy is not to make the per container-mile cost of transporting goods by rail and ship less expensive than truck; rather than that, we should offset the other "costs", such as longer time-of-delivery. We also need to determine what price per container-mile for rail and ship will offset the additional time-of-delivery for these modes [5].

2) Cost and benefit analysis of this policy

The costs of the policy might include the amount of money budgeted for the policy; the wages of the employees that would devise, implement, and evaluate the policy; economic loss to the trucking industry; and potential environmental and social costs from the increased use of rail and ship.

The benefits of the policy might include the social and environmental benefits of reduced $\mathrm{CO}_{2}$ emissions and economic benefits to the rail and ship industries.

3) Stakeholders

The stakeholders related to this policy are government (policy makers), truck companied industry, rail and ship industries, and public.

4) The results this policy can make

The policy would likely result in an increased usage of less carbon-intense modes of freight transport such as rail and ship and a decrease in the use of heavy-duty trucks.

In order to measure the impact of a modal subsidy or grant, we can calculate per container-mile cost for each mode affected by the policy. 
1) Definition

Fuel taxes based on carbon content encourages people to use low-carbon fuels. So the demand of low-carbon fuels will increase; on the other hand, the demand and consumption of high-carbon fuels will decrease. In addition, the "technology" lever will be affected, which push companies and industries to innovate and install fuel-saving technologies.

In order to know the feasibility of this policy, we need to get the data of the cost and benefit as well as the stakeholders' attitude toward the policy.

2) Cost and benefit of this policy

The costs of the policy might include increased economic cost to the truck, rail, and ship industries and increased cost to those industries' customers (note: the additional operating cost would likely be passed on). In addition, the oil demand will decrease, so the oil companies will have economic loss, which should also be considered in the cost analysis.

When doing analysis of the benefits of the policy, we should consider the reduced air pollution, savings for fuel and increased profit to alternative fuel suppliers and developers.

3) Stakeholders

Stakeholders in this case should include government (policy makers), oil companies, freight transport companies (including truck, rail, air and ship companies), and publics.

4) The results this policy can make

The policy is likely result in an increased use of more fuel-efficient modes, such as rail and ship, instead of truck. In addition, it'll push toward technologies that improve fuel economy.

In order to measure the impact of a fuel tax, we would first increase the per-container-mile cost of each mode since operating costs would increase due to the fuel tax. We also want to determine how much each mode's per container-mile cost should be increased in order to make people shift their modes, so data on trucks' fuel economy and energy use, horsepower, and speed of rail and ship would be necessary for us.

In order to encourage mode-shifting, the fuel tax should be determined high enough for shippers to be unwilling to use unimodal truck routes.

\subsubsection{Carbon taxes}

\section{1) Definition}

Carbon taxes are based on the amount of $\mathrm{CO}_{2}$ emitted by vehicles. It encourages people to use the less carbon intensive transport modes, like rail and ship, and lowcarbon fuels. In addition, it encourages people to implement fuel efficient technologies. The carbon taxes are to decrease the demand of carbon-intensive transport modes and high-carbon fuels. It is similar to fuel taxes.

2) Cost and benefit of this policy

The cost of this policy include the more money that companies and people will pay for the freight transport due to the carbon taxes; the cost to implement this policy, including some labor cost; the decreased sales of some oil companies; and the decreased amount of taking truck mode.

The benefit of this policy might include the alleviated air pollution, which can be translated into cost by the "price of $\mathrm{CO}_{2}$ "; increased revenue of government from rail and ship companies; and increased profit of some fuel suppliers.

3) Stakeholders

The stakeholders related to this policy may include government (policy maker); freight transportation companies, including truck, rail, air and ship companies; oil companies; publics.

4) The results this policy can make

The policy would likely result in an increased use of more fuel-efficient modes (like rail and ship versus truck) and a push toward technologies that improve fuel economy.

The amount of the increase for each mode depends on the level of taxation for each unit of $\mathrm{CO}_{2}$ emitted and the efficiency of each mode. We should find the point at which the shipper will find that it is not economic efficient to transport goods by unimodal truck routes, and they'll be pushed to shift to use other modes such as railship intermodal routes.

Because the cost of rail and ship are lower than truck initially, what we can do to push people to not use truck is not decreasing the cost of rail and ship. Instead, we should do some improvement on the delivery of time on the two modes, like improving the facility infrastructure to let it be more efficient and largely decrease the transfer time. People have the VOT (value of time) in their mind, so the tradeoff of time of delivery in of paramount importance.

\subsection{Technology implementation.}

1) Definition

Technology implementation refers to that we implemented advanced technology in order to decrease the $\mathrm{CO}_{2}$ emissions and improve fuel efficiency by the intermodal freight transport industry. For example, lowrolling resistance tires and aerodynamic improvements for heavy duty diesel trucks can improve the fuel efficiency of intermodal freight transport [6].

We need to analyze its cost and benefits, as well as the stakeholders' viewpoint, so as to evaluate whether this policy is attractive or not, and we can estimate whether the stakeholders will support or not.

2) Cost and benefit of this policy

The cost of this policy might be the purchase cost of the technology; the labor cost, including the cost for them to evaluate and implement this policy; and the decreased profit for some fuel companies due to possible decreased fuel consumption.

The benefit of this policy might include revenue for companies that produce the technologies, reduced pollution, and cost savings due to greater fuel economy.

3) Stakeholders

Stakeholders in this case include policy makers (government), companies that produce the technologies, fuel companies, freight transport companies, publics. 
4) The results this policy can make

A technology implementation policy might result in lower $\mathrm{CO}_{2}$ emissions for trucks, due to reduced fuel consumption. This counts to the reduction of the total fuel consumption and $\mathrm{CO}_{2}$ emissions in the intermodal transport process.

\subsection{Legislation.}

Government can act laws related to the freight transport to give enforcement to the environmental. In that way, not only the environmental-concerned people, but all the people will take environmental issues into consideration. For example, government can determine a point $\left(\mathrm{CO}_{2}\right.$ grams $/ \mathrm{TEU} / \mathrm{km}$ ) at which if people arrived they will be fined at a predefined rate.

\section{The benefits of intermodalism and mode-shifting}

All of our policies above are to encourage people to make shift to intermodalism. The benefits of intermodalism and mode-shifting include:

- Lower $\mathrm{CO}_{2}$ emissions;

- Lower economic costs;

- Increased efficiency.

\subsection{Lower $\mathrm{CO}_{2}$ emissions}

Switching to intermodal routes that make use of less carbon-intense modes of freight transport (rail and ship) or switching from unimodal truck routes to unimodal rail and ship routes has the effect of reducing $\mathrm{CO}_{2}$ emissions. Reduction of $\mathrm{CO}_{2}$ emissions results in lower social and environmental costs.

\subsection{Lower economic costs}

Lower $\mathrm{CO}_{2}$ emissions can also lead to economic cost savings if a "price for carbon" is implemented, such as a carbon tax or a cap-and-trade program for $\mathrm{CO}_{2}$ emissions; this results in a lower economic cost. Also, switching to intermodal or unimodal routes that use rail and ship are inherently less expensive due to increased efficiency, that is, more goods (by volume or weight) can be moved by rail and ship compared to truck at a lower price.

\subsection{Increased efficiency}

Switching to intermodal or unimodal routes that make use of rail and ship leads to greater efficiency. Increased fuel efficiency leads to lower fuel consumption.

\section{Limitations}

In order to get the results, we must make some assumptions, such as the fuel economy, horsepower, container capacity, engine load factor, engine efficiency, and speed of the vehicles. However, these assumptions are also limitations. Also, emissions are represented on a per mile basis. No consideration is given to changes in emissions as a function of speed, grade, or load.

\section{Conclusion}

This paper focuses on the impacts and tradeoffs of multi factors associated with intermodal freight transport, including energy, environmental, and economic attributes. In order to let the intermodal transport become sustainably, the untraditional factors such as energy use, $\mathrm{CO}_{2}$ emissions and the efficiency of fuel consumptions should take into consideration. The methods include using VOT and emission calculator to translate the multiple non-monetary factors into cost. In that way, we can make a decision using shortest path model.

In order to motivate people to change their behavior to care about the environment, policies are necessary for us. Policies has it's a series of advantages to encourage people to make mode shift and turn to less polluted way to choose routes. The proposed policies include four aspects, such as infrastructure investment, economic incentives, technology implementation and legislation. Public policies are necessary, because it can address market failures such as negative social and environmental externalities, promote economic growth, and improve national security by reducing our dependence on foreign oil. However, there are both costs and benefits to any policy. We need to determine a point at which shippers will turn to use intermodal transport.

\section{References}

1. M. P. Boile (2000). Intermodal transportation network analysis - A GIS application. Paper presented at the 10th Mediterranean Electro technical Conference

2. J. J. Winebrake; J. J. Corbett, A. Falzarano, J. S. Hawker, K. Korfmacher, S. Ketha, S. Zilora (2008). Journal of the Air \& Waste Management Association, $\mathbf{5 8}(8)$

3. E. Taniguchi, R.G. Thompson (2004). Logistics Systems for Sustainable Cities. Proceedings of the 3rd International Conference on City Logistics

4. K. Trusty, E. Malstrom (1998). A Feasible assessment of Truck-barge Intermodal Freight Transportation. Journal of Costs

5. B. Comer (2009). Sustainable intermodal freight transportation: applying the geospatial intermodal freight transport model

6. Baasankhuu manduul (2007). Preliminary discussion paper on guidance for the developing countries to build a sustainable freight transport system. World Road Association (PIARC) 